\title{
Implementation and Assessment of the Use of Real-Time PCR in Routine Diagnosis for Bordetella pertussis Detection in Brazil
}

\author{
Daniela Leite ${ }^{1,{ }^{*}}$, Roberta Morozetti Blanco ${ }^{1}$, Leyva Cecilia Vieira de Melo ${ }^{1}$, Cleiton Eduardo \\ Fiorio ${ }^{1}$, Luciano Moura Martins ${ }^{1}$, Tania Mara Ibelli Vaz ${ }^{1}$, Sueli Aparecida Fernandes ${ }^{1}$, \\ Claudio Tavares Sacchi ${ }^{2}$ \\ ${ }^{1}$ Center of Bacteriology, National Reference Laboratory for Pertussis, Instituto Adolfo Lutz, Sao Paulo, Brazil \\ 2 Center of Imunology, Instituto Adolfo Lutz, Sao Paulo, Brazil \\ ${ }^{*}$ Corresponding author: Daniela Leite, Center of Bacteriology, National Reference Laboratory for Pertussis, Instituto Adolfo Lutz. Av. Dr. Arnaldo, 351 - $9^{\circ}$ andar, CEP: 01246-902, Sao \\ Paulo-SP, Brazil. Tel:+55-1130682896, Fax: +55-1130819161, E-mail: dedeleite@gmail.com.
}

Received: May 27, 2013; Revised: June 18, 2013; Accepted: August 27, 2013

\begin{abstract}
Background: Bordetella pertussis is the causative agent of pertussis. In Brazil, laboratory diagnosis of pertussis is based on the culture. In 2010, was standardized the Real-Time PCR TaqMan@ in routine diagnosis.

Objectives: The aim of this study was to evaluate the impact achieved with the introduction of RT-PCR for the routine diagnosis of pertussis and to compare with the results obtained from culture.

Patients and Methods: 4,697 samples of nasopharyngeal secretions collected from suspected pertussis cases and/or contacts were analyzed for RT-PCR and culture, from January 2008 until the end of December 2011.

Results: According to the results obtained from the samples 6.9\% were culture/RT-PCR positive, $14.8 \%$ were positive only for RT-PCRand $0.2 \%$ only for culture. Negative samples for both techniques was 3,622 (77.1\%) and 1.0\% were inconclusive for RT-PCR.

Conclusions: The implementation of RT-PCR in routine diagnosis resulted in an increase in laboratory confirmation by almost three times. The RT-PCR assay does not intend to replace the culture technique, but to promote an improvement in the diagnosis of pertussis.
\end{abstract}

Keywords: Bordetella pertussis; Whooping Cough; Diagnosis; Real-Time Polymerase Chain Reaction

\section{Background}

Bordetella pertussis, a Gram negative bacterium, is the causative agent of whooping cough or pertussis, an infectious respiratory disease of worldwide occurrence and high prevalence among newborns and children with incomplete immunization. Currently there are eight species described in the genus Bordetella including B. pertussis, B. parapertussis, B. holmesii and B. bronchiseptica which are the species most commonly associated with respiratory infections in humans, although the last one rarely infects healthy humans (1-4).

Despite mass vaccination programs and good coverage in many countries, $B$. pertussis continues to circulate worldwide and periodically cause epidemics every 3-5 years. Currently, a large number of cases have been reported among adolescents and adults, to be important sources of infection for infants and children $(5,6)$.

High levels of efficiency have been obtained from both whole-cell (wP) or acellular (aP) pertussis vaccines. The duration of protection following the basic vaccination schedule with a booster dose of wP vaccine or natural infection is the same, is estimated to be about 6-12 years. Some studies show that the duration of protection with the use of aP vaccine is situated within the same time range (7).

In Brazil, a vaccination program recommended by Ministry of Health is three doses with tetravalent vaccine: diphtheria, wP and tetanus (DTP) + Hib (Haemophilus influenza $B$ ) at ages 2, 4 and 6 months age and two boosters of DTP, the first at 15-18 months and the second between ages 4 and 6 years ( 8 ).

From 1980 to 1983 more than 40,000 cases of pertussis (incidence rate $>30 / 100,000$ ) were reported in Brazil, but cases decreased substantially after 1983. In 1990, 15,329 cases (incidence rate 10.64/100,000) were reported, the highest rate observed in the decade. In 1995, 3,798 cases (incidence rate $2.44 / 100,000$ ) were reported and, thereafter, the annual number of cases did not exceed 2,000 
(incidence rate 1/100,000). The years 2008 and 2011 reported 1,427 and 2,257 cases (incidence rate 0.71/100,000 and 1.2/100,000) respectively, being considered epidemics years by epidemiological surveillance system of the country (9).

Estimates from the World Health Organization (WHO) suggest that in 2008, about 16 million cases of pertussis occurred worldwide, of which 95\% were in developing countries, where 195,000 children died (10).

The culture is considered the "gold standard" for detection of B. pertussis, it is a highly specific method, but with a variable sensitivity and lengthy incubation periods. When the material collection is performed at symptom onset (3-4 weeks), high rates of isolation of B. pertussis is achieved, but the positivity rate of culture decreases to about $15-20 \%$ with nasopharyngeal secretion collected six weeks after the onset of symptoms (11-13).

Several studies have shown the usefulness of real time polymerase chain reaction (RT-PCR) to detect pathogens. The high sensitivity (70-90\%) and specificity (86-100\%), along with a shorter response time to results, low risk of contamination and ease of performance, makes RT-PCR an alternative method for the diagnosis of many diseases, among them, the pertussis (13-15).

Traditionally, in Brazil, pertussis laboratory diagnosis has been based solely on culture method. Due to the increase in number of notifications of pertussis observed in other countries $(16,17)$ and also in Brazil, for over a decade, there was a need to implement a diagnostic method with higher sensitivity and specificity, with a shorter time to release results. Then, in 2010, we standardized the Real-Time PCR TaqMan® (RT-PCR) in routine diagnosis of Instituto Adolfo Lutz, the national reference center for pertussis in Brazil.

\section{Objectives}

The aim of this study was to evaluate the impact achieved with the introduction of such technology for the routine diagnosis of pertussis in our settings and to compare with the results obtained from culture.

\section{Patients and Methods}

\subsection{Microorganisms Strains}

To evaluate the sensitivity and specificity of RT-PCR, 106 B. pertussis strains and a total of 293 strains of microorganisms were analyzed, to several genera and species, which may be present in the human nasopharynx (Table 1).

The bacterial strains used in this study belong to the collection of bacteriology research center, Instituto Adolfo Lutz (IAL). Other microorganisms used, were provided by the center for interdisciplinary procedures, core collection of microorganisms of the IAL.

\subsection{Clinical Samples and Culture}

We analyzed 4,697 samples of nasopharyngeal secretions collected from patients and/or contacts with suspected pertussis, assisted in the basic health units distributed in all Sao Paulo state, from the beginning of January 2008 until the end of December 2011. Patients and/or contacts were separated into six age-groups: Group 1: $\leq 2$ months ( $n=1,341)$; Group 2:3-6 months ( $n=861)$; Group 3: 7 months - 1 year $(n=368)$; Group 4:2-9 years $(n=453)$; Group 5:10-19 years $(n=409)$ and Group 6: $\geq 20$ years $(n=1,034)$. The age group ranged from eight days old to 85 years old and in 231 patients and/or contacts was not known.

Were considered suspected of pertussis and reported to the surveillance system disease: any person who, without other apparent cause, regardless of vaccination status or age, presented symptoms of infection of the upper airways with cough lasting at least two weeks and with at least one of the following symptoms: (i) paroxysms of coughing, (ii) inspiratory whooping and (iii) post-tussive vomiting (i.e. vomiting immediately after coughing) (18).

Clinical samples were collected with ultrathin and flexible sterile swabs, and immediately placed in a tube with transport Regan-Lowe (RL) medium containing charcoal agar (Oxoid) semi-solid with 10\% sterile defibrinated sheep blood, and Cephalexin $(40 \mu \mathrm{g} / \mathrm{mL})$. The center of bacteriology, Instituto Adolfo Lutz center and the twelve centers of regional laboratories of Instituto Adolfo Lutz (CLRs - IAL) received and processed the swabs collected at basic health units according to their areas of coverage.

The specimens were cultured on the collection day on charcoal agar plates (Oxoid) with sheep blood and Cephalexin incubated at $35-37^{\circ} \mathrm{C}$ under high humidity ambient air for twelve days. The samples that showed growth from the third or fourth day, with colonies suggestive of belonging to the genus Bordetella were confirmed by Gram staining. The biochemical and antigenic characterizations were realized as described previously (19).

After the culture procedure, the swabs were transferred to dried sterile tubes and kept at $-20^{\circ} \mathrm{C}$ for subsequent phase of extraction, purification and concentration of bacterial DNA. The swabs processed for culture in CLRs were sent to IAL Central for RT-PCR performing.

\subsection{Extraction and Purification of Bacterial DNA}

The swabs were thawed, removed from the dry tube and stirred with rotational movements into a $1.5 \mathrm{~mL} \mathrm{mi-}$ cro tube with $200 \mu \mathrm{L}$ of free DNA ultrapure sterile water (Roche Diagnostics, Indianapolis, Ind.). From this step, the extraction was carried out using QIAampDNA Mini Kit (QIAGEN, Valencia, CA) according to the protocol described by the manufacturer. The extracted and purified DNA was eluted in $100 \mu \mathrm{L}$ of the appropriate buffer, provided in the kit. 
Leite D et al.

\begin{tabular}{|c|c|c|c|}
\hline Micro Organisms & No. Tested & Micro Organisms & No. Tested \\
\hline Acinetobacter baumannii & 5 & Mycobacterium flavescens & 1 \\
\hline Alcaligenes xylosoxidans & 5 & Mycobacterium fortuitum & 3 \\
\hline Bordetella pertussis & 106 & Mycobacterium gordonae & 4 \\
\hline Bordetella parapertussis & 3 & Mycobacterium intracellulare & 1 \\
\hline Bordetella bronchiseptica & 1 & Mycobacterium kansasii & 3 \\
\hline Burkholderia cepacia & 3 & Mycobacterium mucogenicum & 1 \\
\hline Corynebacterium diphtheriae & 4 & Mycobacterium peregrinum & 2 \\
\hline Corynebacterium xerosis & 3 & Mycobacterium rhodesiae & 1 \\
\hline Corynebacterium ulcerans & 1 & Mycobacterium tuberculosis & 10 \\
\hline Chlamydia pneumoniae & 1 & Neisseria lactamica & 2 \\
\hline Chlamydia trachomatis & 1 & Neisseria meningitidis & 46 \\
\hline Coccidioides immitis & 1 & Neisseria sicca & 2 \\
\hline Cryptococcus spp & 1 & Neisseria subflava flava & 1 \\
\hline Enterobacter cloacae & 1 & Neisseria subflava perflava & 1 \\
\hline Escherichia coli & 3 & Nocardia asteroides & 1 \\
\hline Enterococcus faecalis & 1 & Pseudomonas aeruginosa & 7 \\
\hline Haemophilus influenzae & 50 & Paraccoccidioides brasiliensis & 1 \\
\hline Haemophilus parainfluenzae & 2 & Salmonella Brandenburgh & 1 \\
\hline Histoplasma capsulatum & 1 & Salmonella Enteritidis & 1 \\
\hline Klebsiella pneumoniae & 1 & Salmonella Typhimurium & 1 \\
\hline Listeria monocytogenes & 13 & Stenotrophomonas maltophilia & 3 \\
\hline Legionella spp & 1 & Staphylococcus aureus & 2 \\
\hline Moraxella catarrhalis & 3 & Staphylococcus epidermidis & 1 \\
\hline Mycobacterium avium & 5 & Streptococcus agalactiae & 1 \\
\hline Mycobacterium abscessus & 4 & Streptococcus pneumoniae & 25 \\
\hline Mycobacterium bohemicum & 1 & Streptococcus pyogenes & 3 \\
\hline \multirow[t]{2}{*}{ Mycobacterium bovis } & 1 & Streptococcus group Viridans & 52 \\
\hline & & Total & 399 \\
\hline
\end{tabular}

Was used reference strain of B. pertussis GL353 received from the reference laboratory of the World Health Organization for Pertussis - University of Manchester - England, as positive control for all RT-PCR reactions.

The DNA of GL353 was extracted and the DNA concentration and purity were determined using equipment NanoDrop ® 2000 spectrophotometer (Thermo Scientific), absorbance at $260 \mathrm{~nm}$, with an average value of $303.42 \mathrm{ng} / \mathrm{\mu L}$.

At each step of extraction of clinical samples, was performed an extraction of a sterile swab simultaneously, as a false positive control result due to cross-contamination, since this sample will be necessarily negative in all reaction.

\subsection{RT-PCR}

We used RT-PCR assay as described by Tatti et al.(13) with a minor modifications, based on the detection of the toxin gene ptxS1 (GenBank accession $n^{\circ}$ AJ920066) and the insertion sequence of IS481 (GenBank accession $n^{\circ}$ M22031). We also used the human rnaseP gene (GenBank accession $n^{\circ}$ ACC NM006413) as control of the absence of inhibitors of RT-PCR and to monitor the efficiency of extraction of clinical material.

The probes were labeled at the 5' position with 6-carboxyfluorescein (FAM) and 3' position with Black Hole Quencher 1(BHQ1) (Table 2).

\subsection{Amplification}

Real-time PCR was performed with the 7300 Real-Time PCR system instrument (Applied Biosystems). A total reaction volume of $25 \mu \mathrm{L}$ was used in each one of the reactions to all samples containing from $5 \mu \mathrm{L}$ of bacterial DNA extracted and purified, and $12.5 \mu \mathrm{L}$ of $2 \mathrm{X}$ TaqMan Master Mix Universal (Universal PCR Master Mix - Applied Biosystems), $2 \mu \mathrm{L}$ of each primer (forward and reverse) at 300 
Leite D et al.

\begin{tabular}{|c|c|c|c|c|}
\hline Target & Primer/Probe & Sequence $5^{\prime}-3^{\prime}$ & Amplicon Length (bp) & $\begin{array}{l}\text { Optimal Concentration } \\
\text { per Reaction }(\mathrm{nM})\end{array}$ \\
\hline \multirow[t]{4}{*}{$p t x S 1^{\mathrm{a}}$} & & & 55 & \\
\hline & $402 \mathrm{U} 16$ & CGCCAGCTCGTACTTC & & 300 \\
\hline & 442L15 & GATACGGCCGGCATT & & 300 \\
\hline & $419 \mathrm{U} 22 \mathrm{P}^{\mathrm{d}}$ & AATACGTCGACACTTATGGCGA & & 100 \\
\hline \multirow[t]{4}{*}{ IS481 } & & & 66 & \\
\hline & 852U18 & CAAGGCCGAACGCTTCAT & & 300 \\
\hline & 894L24 & GAGTTCTGGTAGGTGTGAGCGTAA & & 300 \\
\hline & $871 \mathrm{U} 22 \mathrm{P}^{\mathrm{d}}$ & CAGTCGGCCTTGCGTGAGTGGG & & 100 \\
\hline \multirow[t]{4}{*}{$\operatorname{rnase} P^{C}$} & & & 65 & \\
\hline & F primer & AGATTTGGACCTGCGAGCG & & 300 \\
\hline & R primer & GAGCGGCTGTCTCCACAAGT & & 300 \\
\hline & Probe $^{\mathrm{d}}$ & TTCTGACCTGAAGGCTCTGCGCG & & 100 \\
\hline
\end{tabular}

$\mathrm{nmol} / \mathrm{mL}, 2 \mu \mathrm{l}$ of the probe at $100 \mathrm{nmol} / \mathrm{mL}$ and $1.5 \mu \mathrm{L}$ of PCR grade water (Roche Diagnostics, Indianapolis, Ind.). The PCR protocol used was as follows: 1 cycle of 2 min at $50^{\circ} \mathrm{C}$; activation of the enzyme by $10 \mathrm{~min}$ at $95^{\circ} \mathrm{C}$, and 45 cycles of $15 \mathrm{sec}$ at $95^{\circ} \mathrm{C}$ and $1 \mathrm{~min}$ at $57^{\circ} \mathrm{C}$ each.

All samples were tested in duplicate and two wells for positive control were included in each reaction (GL353 strain), two wells for negative control (sterile swab) and four controls without DNA (two for preparation area and two reaction area applying DNA). These controls were tested to rule out the possibility of amplification failure or contamination.

Data collection was performed at the stage of extension to $57^{\circ} \mathrm{C}$. The results were analyzed by the platform software systems 7300 , sequence detection software (SDS) version 1.2.3 (Applied Biosystems).

\subsection{Lower Limit of Detection (LLD)}

The LLD was calculated in duplicate using DNA extracted and purified from the reference strain of B. pertussis GL353. The DNA was diluted in water to a concentration of $10 \mathrm{ng} / \mu \mathrm{L}$. From this dilution, the DNA was diluted in serial 10 -fold dilutions until a dilution of $10-8$ or $0.1 \mathrm{fg} / \mu \mathrm{L}$.

\subsection{Interpretation of Results}

For this study, cut-off for positive, negative and inconclusive results were defined based on "Cycle Threshold" (Ct) values. The reactions of IS481 and ptxS1 were analyzed separately and were considered positive values as cut-off
Ct $\leq 39$ for gene $p t x S 1$ and $\leq 29$ for gene IS481; Ct values equal to zero or greater than or equal to 42 ( ptxS1) and 32 (IS481) were considered negative, while values between 40-41 and 30-31 were considered inconclusive for ptxS1 and IS481 respectively. The algorithms for interpretation of results are stated in Table 3. Specimens were considered positive for the presence of $B$. pertussis if amplification occurred with both targets. No attempt was made to identify species other than B. pertussis in this work.

This study was approved by the research ethics committee of the Instituto Adolfo Lutz (protocol number 024/2009 - CCD-BM 09/07).

\section{Results}

All 106 B. pertussis strains used for evaluation of sensitivity were positive by IS481 and ptxS1 targets; all 293 strains of other microorganisms analyzed for evaluation of specificity were negative for both genes (Table 1).

The LLD for the assay was determined to be $20 \mathrm{fg}$ for both genes with dilution that yield a Ct value less than or equal to the cut-off of 39 and 29 for ptxS1 and IS481, respectively. It was defined as a dilution acceptable variation above or below the LLD established.

The tests had efficiency of $91.4 \%$ with a slope of -3.55 for the gene $p t x S 1$ and efficiency of $85.2 \%$ with a slope of -3.74 for the gene IS481. The slope of the log-linear phase of the amplification reaction is a measure of reaction efficiency. To obtain accurate results, reactions should have efficiency as close to $100 \%$ as possible, equivalent to a slope of -3.32 . The number of samples tested in this study was $301,274,852$ and 3,270 with percentual of positive tests of 
Leite D et al.

\begin{tabular}{|c|c|c|}
\hline IS481 & ptxS1 & Interpretation \\
\hline+ & + & B. pertussis ${ }^{\mathrm{a}}$ \\
\hline - & - & $\begin{array}{l}\text { Negative for } B \text {. } \\
\text { pertussis }\end{array}$ \\
\hline- & Inc $^{\mathrm{b}}$ & $\begin{array}{l}\text { Negative for } B \text {. } \\
\text { pertussis }\end{array}$ \\
\hline Inc & - & $\begin{array}{l}\text { Negative for } B \text {. } \\
\text { pertussis }\end{array}$ \\
\hline+ & Inc & Inconclusive $^{\mathrm{c}}$ \\
\hline Inc & + & Inconclusive $^{\mathrm{C}}$ \\
\hline Inc & Inc & Inconclusive $^{c}$ \\
\hline+ & - & Inconclusive $^{c}$ \\
\hline - & + & Inconclusive $^{c}$ \\
\hline
\end{tabular}

26.6\%, 16.8\%, 17.7\% and 22.7\% in 2008, 2009, 2010 and 2011, respectively. According to the results obtained from the 4,697 swabs analyzed, 21.9\% (1,028) were positive in RTPCR and/or culture tests, being: 325 (6.9\%) positive using both growth culture and RT-PCR, 694 (14.8\%) were posi- tive to RT-PCR and negative for culture and eight (0.2\%) were positive for culture but not to RT-PCR. Samples negative for both techniques totaled 3,622 (77.1\%); among 48 samples inconclusive by RT-PCR, 47 (1.0\%) were negative for culture and one was positive for this method (Table 4).

Table 4. Results of Culture and RT-PCR of 4,697 Nasopharyngeal Samples Collected from January 2008 to December 2011

\begin{tabular}{llll}
\hline Methods & \multicolumn{2}{c}{ Culture, No. (\%) } & Total \\
\hline Real-Time PCR & Positive & Negative & \\
Positive & $325(6.9)$ & $694(14.8)$ & $1,019(21.7)$ \\
Negative & $8(0.2)$ & $3,622(77.1)$ & $3,630(77.3)$ \\
Inconclusive & $1(0)$ & $47(1)$ & $48(1)$ \\
Total & $334(7.1)$ & $4,363(92.9)$ & $4,697(100)$ \\
\hline
\end{tabular}

All 4,363 samples culture negative for B. pertussis, were also negative for other Bordetella species. Results of rnaseP gene demonstrated absence of inhibitors of RTPCR in all samples tested.

Characteristics according to age groups and laboratory results (culture and Real time PCR assays) are shown in Table 5. All results, after its registration in IAL Central, were released within 15 days and 24-48 hours for culture and RT-PCR respectively.

\begin{tabular}{|c|c|c|c|c|c|c|c|}
\hline \multirow[t]{2}{*}{ Age Group } & \multirow[t]{2}{*}{$\operatorname{Mean}\left(\mathbf{S D}^{\mathrm{a}}\right)$} & \multicolumn{3}{|c|}{ Real Time PCR, No. (\%) } & \multicolumn{2}{|c|}{ Culture, No. (\%) } & \multirow{2}{*}{$\begin{array}{l}\text { Total Ana- } \\
\text { lyzed, No. }(\%)\end{array}$} \\
\hline & & Positive & Negative & Inconclusive & Positive & Negative & \\
\hline Group $1(\leq 2 \mathrm{~m})$ & $1.4(0.5)$ & $507(37.8)$ & $818(61.0)$ & $16(1.2)$ & $160(11.9)$ & $1,181(88.1)$ & $1,341(28.6)$ \\
\hline Group 2 (3-6 m) & $4.0(1.0)$ & $254(29.5)$ & $593(68.9)$ & $14(1.6)$ & $78(9.1)$ & $783(90.9)$ & $861(18.3)$ \\
\hline Group 3 (7 mo-1 y) & $8.5(1.4)$ & $69(18.8)$ & $298(81.0)$ & $01(0.3)$ & $23(6.3)$ & $345(93.8)$ & $368(7.8)$ \\
\hline Group 4 (2-9 y) & $4.7(2.4)$ & $41(9.1)$ & $409(90.3)$ & $03(0.7)$ & $10(2.2)$ & $443(97.8)$ & $453(9.6)$ \\
\hline Group 5 (10-19 y) & $14.3(2.9)$ & $35(8.6)$ & $370(90.5)$ & $04(1.0)$ & $20(4.9)$ & $389(95.1)$ & $409(8.7)$ \\
\hline Group 6 ( $\geq 20$ y) & $35.0(12.8)$ & $91(8.8)$ & $935(90.4)$ & $08(0.8)$ & $38(3.7)$ & $996(96.3)$ & $1,034(22.0)$ \\
\hline No Information & & $22(9.5)$ & $207(89.6)$ & $02(0.9)$ & $05(2.2)$ & $226(97.8)$ & $231(4.9)$ \\
\hline Total & & $1,019(21.7)$ & $3,630(77.3)$ & $48(1.0)$ & $334(7.1)$ & $4,363(92.9)$ & $4,697(100)$ \\
\hline
\end{tabular}

a Abbreviation: SD, standard deviation.

\section{Discussion}

Several PCR protocols have been developed in recent years for different targets in the genome of B. pertussis like an insertion sequence IS481, pertussis toxin gene promoter (ptxA-Pr), pertussis toxin S1 subunit (ptxS1), porin gene, pertactin filaments hemagglutinin gene and adenylate cyclase $(14,15,20,21)$. Many laboratories use the insertion sequence IS481 in PCR assays to determine the presence of $B$. pertussis DNA. This sequence is often the target of choice because it is found in multiple copies in the genome of $B$. pertussis (50-238 copies per genome), making this test much more sensitive. However, because of its high copy number, false positive results may be generated and positive results using only a target may lead to a false diagnosis of pertussis $(15,22,23)$. The IS481 is also present in B. holmesii (8-10 copies per genome) and in $B$. Bronchiseptica, but the presence of IS481 is host dependent in this specie and is found in several animals, being rare human isolates (24).

PCR assays using only IS481 target, may be useful as screening techniques and can improve the sensitivity of the test, but have limited clinical value, especially in outbreak situations and can substantially decrease the 
specificity. A positive test for IS481 requires additional testing, using assays that detect toxin gene, pertactin or other targets specific to B. pertussis, may be useful in interpreting the results for confirmation of the species. An isolated result for IS481 should be reported as negative or inconclusive for $B$. pertussis if there isn ${ }^{\top} t$ possibility of a target additional $(13,15,25)$.

In this study we used two target genes; IS481 and ptxS1 to improve the sensitivity and specificity of the test and to increase the accuracy and ensure an interpretation of a result to $B$. pertussis more reliable.

We identified 694 samples as B.pertussis, since it showed positive results for both researched targets; IS481 and ptxS1 in RT-PCR. Despite these samples have shown negative results for culture, it was considered positive in the final result. All samples that had tested positive for one gene and inconclusive/negative to another gene or inconclusive for both genes investigated were deemed inconclusive, by the algorithm defined. Between 4,697 nasopharyngeal secretion samples analyzed, only $1 \%$ had inconclusive results using RT-PCR. The inconclusive result for both genes does not completely rule out the chance to be a B. pertussis, since the IS481 and/or ptxS1 were not negative, only showed a high $\mathrm{Ct}$.

Nine out of the 4,697 samples tested showed positive results for culture and negative/inconclusive to RT-PCR. These samples were re-tested by RT-PCR and the same result was obtained. Then, the RT-PCR was made from the bacterial suspensions from the culture to rule out the possibility of the genetic targets of RT-PCR being altered by some genetic event in these nine samples, which could explain the negative results. The results of RT-PCR from these suspensions were positive. We do not know the reasons justifying these discordant results, however, it may be due to: (i) the amount of material on the swab, poor or absent at the time of extraction of bacterial DNA, since the swab collected is processed first for the culture, (ii) error in DNA extraction, as the swab after being used for DNA extraction is dropped, there wasn ${ }^{-} t$ the possibility of performing a new extraction in these nine samples.

In the literature, few studies have reported cases of culture positive and PCR negative and most of them interpreted these results as: unequal division of sample to both techniques; flaw in the procedure of DNA extraction and PCR inhibitors in the reactions (26). Similar results were obtained from Tatti et al. (13) and Gullsby et al. (27). These authors suggest that the discrepancy can be explained by low amounts of $B$. pertussis in these samples or DNA degradation by cycles of freezing and thawing in which the samples were submitted. In our study, it is possible that any of these factors or their combination may explain the cause of these nine samples being positive culture and negative RT-PCR, but the hypothesis of degradation of DNA by cycles of freezing and thawing can be discarded, since our samples have not gone through this process.

In relation to age, it is expected that the higher rates of positivity of pertussis are among samples collected from children under two months of age, still not immunized, then the group of children under six months of age, where most children have incomplete immunization, thus becoming vulnerable to more easily acquire the disease. Our results showed that, in fact, the positivity in children under six months was higher than in the other age groups.

A possible limitation of the study concerns the failure to obtain the information about the time interval between the start of disease and sampling, state of vaccination of the study cases and if the patient suspected had started the antibiotic treatment before sampling or not.

The use of the technique of RT-PCR in IAL Central to diagnosis of pertussis has provided high sensitivity relation to other laboratory methods, like a culture. It was responsible for the diagnosis of 685 positive cases by criteria laboratorial more than culture. With these positive results diagnostic for pertussis, can obtain benefits like detect and avoid possible transmission of the disease for new cases, suitable treatment to patients and prophylaxis of contacts, as well as better control and prevention of outbreaks.

In conclusion, the implementation of the new technique in routine diagnostic resulted in an increase in laboratory confirmation by almost three times, in addition to a fast release of the results of 15 days of culture, for 24 - 48 hours for this technique. Then, the RT-PCR assay does not intend to replace the culture technique, but to promote an improvement in the diagnosis of pertussis.

\section{Acknowledgements}

The authors thank Maria Lucia Tondella from the Centers for Diseases Control and Prevention - CDC, for sending the primers / probes used in the initial phase of this study; Luis Fernando dos Santos for reviewing this manuscript and the Pertussis Study Group of the Centers of Regional Laboratories of Instituto Adolfo Lutz, for sending the swabs to perform the real-time PCR and for making available the results of culture.

\section{Authors' Contribution}

Daniela Leite: analysis, interpretation of data and wrote the manuscript. Leyva C. Mello, Luciano M. Moura, Sueli A. Fernandes, Tania M. I. Vaz: procedures laboratorials for culture. Cleiton E. Fiório, Roberta M. Morozetti: procedures laboratorials for Real Time PCR. Claudio T. Sacchi: developed the original idea and the protocol. We also thank to group of the Respiratory Branch - Epidemiological Surveillance System of Sao Paulo State. 


\section{Financial Disclosure}

The authors declare no conflict of interests.

\section{Funding/Support}

The funding organizations are public institutions and had no role in the design and conduct of the study; collection, management, and analysis of the data; or preparation, review, and approval of the manuscript. The Instituto Adolfo Lutz provided practical support for the focus group and survey processes and assistance with logistic arrangements for focus group sessions.

\section{References}

1. Mattoo S, Cherry JD. Molecular pathogenesis, epidemiology, and clinical manifestations of respiratory infections due to Bordetella pertussis and other Bordetella subspecies. Clin Microbiol Rev. 2005;18(2):326-82.

2. Brenner DJ, Krieg NR, Staley JT. The Proteobacteria (Part C): the Alpha-, Beta-, Delta-, and Epsilonproteobacteria. Garrity GM. Bergey's Manual of Systematic Bacteriology. New York: Springer; 2005. p. 1059-144.

3. Gross R, Keidel K, Schmitt K. Resemblance and divergence: the "new" members of the genus Bordetella. Med Microbiol Immunol. 2010;199(3):155-63.

4. Wirsing von Konig CH, Riffelmann M, Coenye T. Bordetella and related genera . In: Versalovic J, Carrol KC, Funke G, Jorgensen JH, Landry ML, Warnock DW, editors. Manual of Clinical Microbiology. 10th ed. Washington: American Society for Microbiology; 2011. pp. 739-50.

5. Tan T, Trindade E, Skowronski D. Epidemiology of pertussis. Pediatr Infect Dis J. 2005;24(5 Suppl):S10-8.

6. Leber AL, Salamon DP, Prince HE. Pertussis diagnosis in the 21st century: progress and pitfalls, part I. Clin Micro Newsletter 2011;33(15):111-5.

7. de Carvalho AP, Pereira EM. Acellular pertussis vaccine for adolescents. J Pediatr (Rio J). 2006;82(3 Suppl):S15-24.

8. Paulo S. [Secretaria de Estado da Saúde. Coordenadoria de Controle de Doenças (CCD). Programa Estadual de Imunização]. BEPA. 2006;3(27):27-8

9. Ministério da Saúde. Available from: http://portal.saude.gov.br/ portal/saude/profissional/area.cfm?id_area=1546.

10. Pertussis vaccines: WHO position paper. Wkly Epidemiol Rec 2010;85(40):385-400

11. Regan J, Lowe F. Enrichment medium for the isolation of Bordetella.J Clin Microbiol. 1977;6(3):303-9.

12. Qin X, Turgeon DK, Ingersoll BP, Monsaas PW, Lemoine CJ, Tsosie $\mathrm{T}$, et al. Bordetella pertussis PCR: simultaneous targeting of signature sequences. Diagn Microbiol Infect Dis. 2002;43(4):269-75.
13. Tatti KM, Wu KH, Tondella ML, Cassiday PK, Cortese MM, Wilkins $\mathrm{PP}$, et al. Development and evaluation of dual-target real-time polymerase chain reaction assays to detect Bordetella spp. Diagn Microbiol Infect Dis. 2008;61(3):264-72.

14. Kosters K, Reischl U, Schmetz J, Riffelmann M, Wirsing von Konig $\mathrm{CH}$. Real-time LightCycler PCR for detection and discrimination of Bordetella pertussis and Bordetella parapertussis. J Clin Microbiol. 2002;40(5):1719-22.

15. Loeffelholz M. Towards improved accuracy of Bordetella pertussis nucleic acid amplification tests. J Clin Microbiol. 2012;50(7):2186-90.

16. Epidemiological Alert Pertussis (whooping cough) 02 march 2012. Available from: Available from: http://new. paho.org/hq/index.php?option=com_docman\&task=doc_ view\&gid=17051\&Itemid=1091.

17. Bottero D, Griffith MM, Lara C, Flores D, Pianciola L, Gaillard ME et al. Bordetella holmesii in children suspected of pertussis in Argentina. Epidemiol Infect. 2013;141(4):714-7.

18. de Vigilância Epidemiológica Guia, da Filariose Linfática Eliminacão. Ministério da Saúde. Fundaçâo Nacional de Saúde. Brasil. 2005.

19. Goncalves CR, Vaz TM, Medeiros MI, Castro MT, Rocha MM, Melles $\mathrm{CE}$, et al. Phenotypical and genotypical characterization of Bordetella pertussis strains isolated in Sao Paulo, Brazil, 1988-2002. Rev Inst Med Trop Sao Paulo. 2007;49(2):123-5.

20. Roorda L, Buitenwerf J, Ossewaarde JM, van der Zee A. A real-time PCR assay with improved specificity for detection and discrimination of all clinically relevant Bordetella species by the presence and distribution of three Insertion Sequence elements. BMC Res Notes. 2011;4:11.

21. Templeton KE, Scheltinga SA, van der Zee A, Diederen BM, van Kruijssen A, Goossens H, et al. Evaluation of real-time PCR for detection of and discrimination between Bordetella pertussis, Bordetella parapertussis, and Bordetella holmesii for clinical diagnosis.J Clin Microbiol. 2003;41(9):4121-6.

22. Tatti KM, Sparks KN, Boney KO, Tondella ML. Novel multitarget real-time PCR assay for rapid detection of Bordetella species in clinical specimens. J Clin Microbiol. 2011;49(12):4059-66.

23. Tatti KM, Tondella ML. Utilization of multiple real-time PCR assays for the diagnosis of Bordetella spp. in clinical specimens. Methods Mol Biol. 2013;943:135-47.

24. Register KB, Sanden GN. Prevalence and sequence variants of IS481 in Bordetella bronchiseptica: implications for IS481-based detection of Bordetella pertussis. JClin Microbiol. 2006;44(12):4577-83.

25. Menard A, Lehours P, Sarlangue J, Bebear C, Megraud F, de Barbeyrac B. Development of a real-time PCR for the identification of Bordetella pertussis and Bordetella parapertussis. Clin Microbiol Infect. 2007;13(4):419-23.

26. Knorr L, Fox JD, Tilley PA, Ahmed-Bentley J. Evaluation of realtime PCR for diagnosis of Bordetella pertussis infection. BMC Infect Dis. 2006; 6:62.

27. Gullsby K, Hallander HO, Bondeson K. Performance of Bordetella pertussis IS481 real-time PCR in a vaccine trial setting. APMIS 2007;115(12):1370-5. 